\title{
Recent Performance In Singapore's Tourism Industry Usingnormality Test, Correlation\& Regression Analysis: The Effect Of Medical Tourism, Service Sector \& Exchange Rate
}

\author{
INTAN MAIZURA ABD RASHID ${ }^{1}$ \\ UNIVERSITI TEKNOLOGI MARA, ALOR GAJAH, MELAKA, MALAYSIA \\ intanmaizuraar@gmail.com \\ SURAIYA IBRAHIM ${ }^{2}$ \\ UNIVERSITI MALAYSIA PERLIS, MALAYSIA \\ WAN SALLHA YUSOFF ${ }^{3}$ \\ UNIVERSITI MALAYSIA PERLIS, MALAYSIA
}

\begin{abstract}
:
The shocking worldwide transmission of COVID-19 has encouraged many governments to interfere to avoid the spread of the infection. Medical tourism is a growing phenomenon with policy implications for health systems, particularly of destination countries. Medical tourism, a rapidly growing market, has been recognized by many countries as a potential sector for economic diversification. Although Singapore stands out as one of the top destinations of medical tourism, investigation regarding its competitiveness has been limited and narrow in scope. This case study takes a quantitative approach to identify and analyze the factors that position Singapore as a competitive medical tourism destination. Based on a holistic approach, this study has shown that integrating diverse strategies for medical tourismdevelopment with sound government policies and proactive management practices have led to significant positive outcomes towards mutual success of tourism and healthcare sectors of Singapore. Additionally, the study provides strategic insights to drive lasting improvements in medical tourism, exchange rare and service sectors through efficient management and intelligent utilization of resources in tourism sector.
\end{abstract}

Keywords:

Tourism Performance, Medical Tourism, Service Sector, Exchange Rate, Singapore.

\section{SINGAPORE'S MEDICAL TOURISM INDUSTRY}

Medical tourism has steadily increased by 2010, three decades later, the Malaysian diaspora in Singapore had reached 385,979.19, and Singapore has gained from Malaysian talent employed across a vast array of sectors in the country. In 2017, Malaysia recorded close to 12.4 million tourist arrivals from Singapore, making the city-state by far the largest source of visitor arrivals. While visitors from Singapore may stay shorter periods of time than visitors from other countries, it is notable that the city-state accounts for substantially more than the combined arrivals from China, Hong Kong, Japan, US and all of Europe. Demographic change, especially population ageing and older people's requirements for more medical services, coupled with epidemiological change, i.e. waiting times or the increasing cost of health services at home, coupled with the availability of cheaper alternatives in developing countries, has lead new healthcare consumers, or medical tourists, to seek treatment overseas. 
In Southeast Asia, the health sector is expanding rapidly, attributable to rapid growth of the private sector and notably, medical tourism, which is emerging as a lucrative business opportunity. Countries here are capitalizing on their popularity as tourist destinations by combining high quality medical services at competitive prices with tourist packages. Some countries are establishing comparative advantages in service provision based on their health system's organizational structure. In Singapore, Malaysia and Thailand alone, an estimated 2 million medical travelers visited in 2006 to 2007, earning these countries over US\$ 3 billion in medical tourism sector.

\section{RESEARCH METHODOLOGY}

The descriptive Statistic Analysis are for data analysis expressed the quantity of the perception that is part required to mention the objective based on the information that being gathered. The analysis are performed by the descriptive static to research out the statistics of the each variable involved here which is medical tourism, exchange rate, service sector growth and tourism sector performance. Then there are included the mean for each data of these variable and are included the standard deviation of the mean data. Furthermore, there are a minimum and a maximum quantity, Kurtosis and Skewness of the data that are used.

\section{Descriptive Statistics Analysis}

Table 1: Descriptive statistics

\begin{tabular}{|c|c|c|c|c|}
\hline & $\begin{array}{c}\text { Singapore } \\
\text { Tourism } \\
\text { Performance } \\
\text { (current US\$) }\end{array}$ & $\begin{array}{l}\text { Exchange } \\
\text { Rate }\end{array}$ & $\begin{array}{c}\text { Medical } \\
\text { Tourism } \\
\text { (current US\$) }\end{array}$ & $\begin{array}{c}\text { Services, } \\
\text { value added (\% } \\
\text { of GDP) }\end{array}$ \\
\hline Mean & $\begin{array}{r}1092725000 \\
0\end{array}$ & 1.497 & 1230666667 & 66.099 \\
\hline Standard Error & 1263024456 & 0.037 & 141736905 & 0.685 \\
\hline Median & 8338500000 & 1.436 & 1421500000 & 65.459 \\
\hline $\begin{array}{l}\text { Standard } \\
\text { Deviation }\end{array}$ & 6187530899 & 0.182 & 694366190 & 3.356 \\
\hline Minimum & 3842000000 & 1.249 & 286000000 & 60.665 \\
\hline Maximum & $\begin{array}{r}2041600000 \\
0\end{array}$ & 1.792 & 2323000000 & 70.759 \\
\hline Count & 24 & 24 & 24 & 24 \\
\hline
\end{tabular}

From the above table, all those variables have the range of 24 observations for Singapore. At first, this study will discuss about mean and standard deviation. Medical tourism has the highest standard deviation and mean. The high value of standard deviation indicates that the data points in this research, medical tourism are spread out at a wider range. The mean for medical tourism is US\$ $1,230,666,667$ and the value for standard deviation is US\$ $694,366,190$ based on the data distribution. The lowest standard deviation and mean is exchange rate where the value for mean is 1.497 and standard deviation is 0.182 . The lowest value of standard deviation indicates that the data points in this research is exchange rate are spread out at a very little range. The other variable besides medical tourism and exchange rate falls in the middle range between these two variable. Besides that, the value for both 
maximum and minimum data for all the variables that being studied in this research paper are also been presented in the table above. The variable that has the highest maximum value is tourism performance. Exchange rate has the lowest minimum value that is 1.249. Service sector with minimum value of 60.66 and maximum value of 70.76 .

\section{Normality Test (Skewness and Kurtosis)}

From Table 2, Kurtosis and Skewness values were used to check the normality of each variable used in the research. Skewness values larger than $(+1)$ or smaller than $(-1)$, as suggested by Hair et al (2003) indicate a substantially skewed distribution. Besides Hair et al (2005) added that a curve is too peaked when theKurtosis exceeds $(+3)$ and is too flat when it is below (-3). This means Skewness values within the range of $(-1)$ to $(+1)$ and Kurtosis values within the range of $(-3)$ to $(+3)$ indicate an acceptable range. As shown in Table 2 , the values of Skewness and Kurtosis for each variable indicate that the research constructs fell within the acceptable range.

Table 2: Normality Test Singapore

\begin{tabular}{|l|c|c|c|c|}
\hline & $\begin{array}{c}\text { Tourism } \\
\text { Performance } \\
\text { (current US\$) }\end{array}$ & $\begin{array}{c}\text { Exchange } \\
\text { Rate }\end{array}$ & $\begin{array}{c}\text { Medical } \\
\text { Tourism (current } \\
\text { US\$) }\end{array}$ & $\begin{array}{c}\text { Services, } \\
\text { value added (\% } \\
\text { of GDP) }\end{array}$ \\
\hline Kurtosis & -1.604921078 & - & -1.619921455 & - \\
& 0.44852999 & 0.277225 & -0.044048448 & 1.612134595 \\
\hline Skewness & 497 & & 0.01800476 \\
\hline
\end{tabular}

\section{Correlation of Variables in Study}

These correlation of the factors in the connection among every variable incorporated the relationship between both the dependent variable and the independent variable that is being analysed in this research study. Correlation is the relationship between the medical tourism and tourism sector performance in Singapore.

Table 3: Correlation of variables in study for Singapore

\begin{tabular}{|c|c|c|c|c|}
\hline Singapore & $\begin{array}{c}\text { Tourism } \\
\text { Performance } \\
\text { (current US\$) }\end{array}$ & $\begin{array}{l}\text { Exchange } \\
\text { Rate }\end{array}$ & $\begin{array}{l}\text { Medical } \\
\text { Tourism } \\
\text { (current } \\
\text { US\$) }\end{array}$ & $\begin{array}{c}\text { Services, } \\
\text { value added } \\
(\% \text { of GDP })\end{array}$ \\
\hline $\begin{array}{l}\text { Tourism Performance } \\
\text { (current US\$) }\end{array}$ & 1 & & & \\
\hline Exchange Rate & -0.871 & 1 & & \\
\hline $\begin{array}{l}\text { Medical Tourism (current } \\
\text { US\$) }\end{array}$ & 0.882 & -0.719 & 1 & \\
\hline $\begin{array}{l}\text { Services, value added (\% } \\
\text { of GDP) }\end{array}$ & 0.909 & -0.749 & 0.913 & 1 \\
\hline
\end{tabular}

The correlation value from the range of 0.719 to 0.909 is considered as a strong correlation. The variables are service sector with medical tourism is 0.913 , the service sector with tourism 
performance is 0.909 , the medical with tourism performance is 0.882 . Besides that, the table 3 also show that there is a low or poor correlation between two variables in this research paper. The negative strong correlation value has the range from below than 1 or also any negative value. The variables that has the high correlation value and show a negative relationship is medical tourism and exchange rate with the value of -0.719 and service sector and exchange rate with the value of -0.749 . Therefore, from the results it can concludes that all of variables are of significant importance to the study.

\section{Normal Probability Plot of Residuals Analysis in Regression}

Initially analysis was performed by researchers using MATLAB [16-21], but at the same time non engg researchers just visualized their results using Excel or other way [22-25]. We have choosen second option here for visualization. The structure evident in these residual plots also indicates potential problems with different aspects of the model. Under ideal circumstances, the plots in the top row would not show any systematic structure in the residuals. Taken at face value, the structure seen here indicates a time trend in the data, autocorrelation of the measurements, and a non-normal distribution of the residuals. It is likely, however, that these plots will look fine once the function describing the systematic relationship between load and deflection has been corrected. Problems with one aspect of a regression model often show up in more than one type of residual plot.

Table 4 : Exchange Rate, Medical Tourism\& Service Sector Growth Residual Plot for Singapore

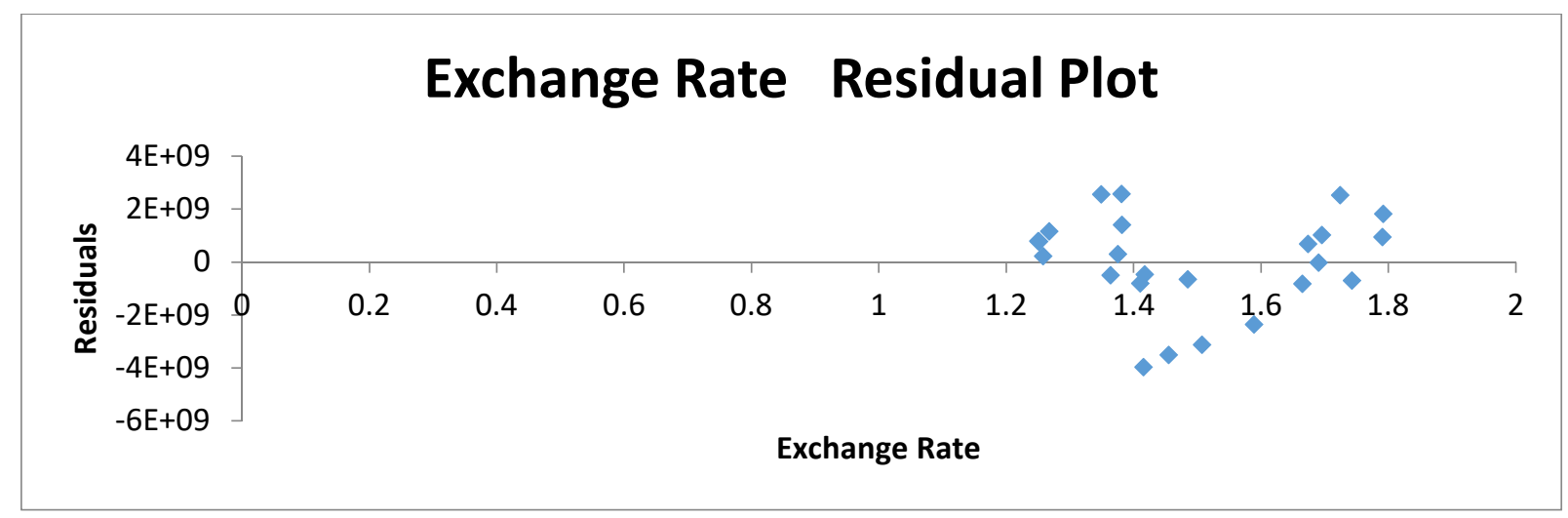




\section{Medical Tourism (current US\$) Residual Plot}
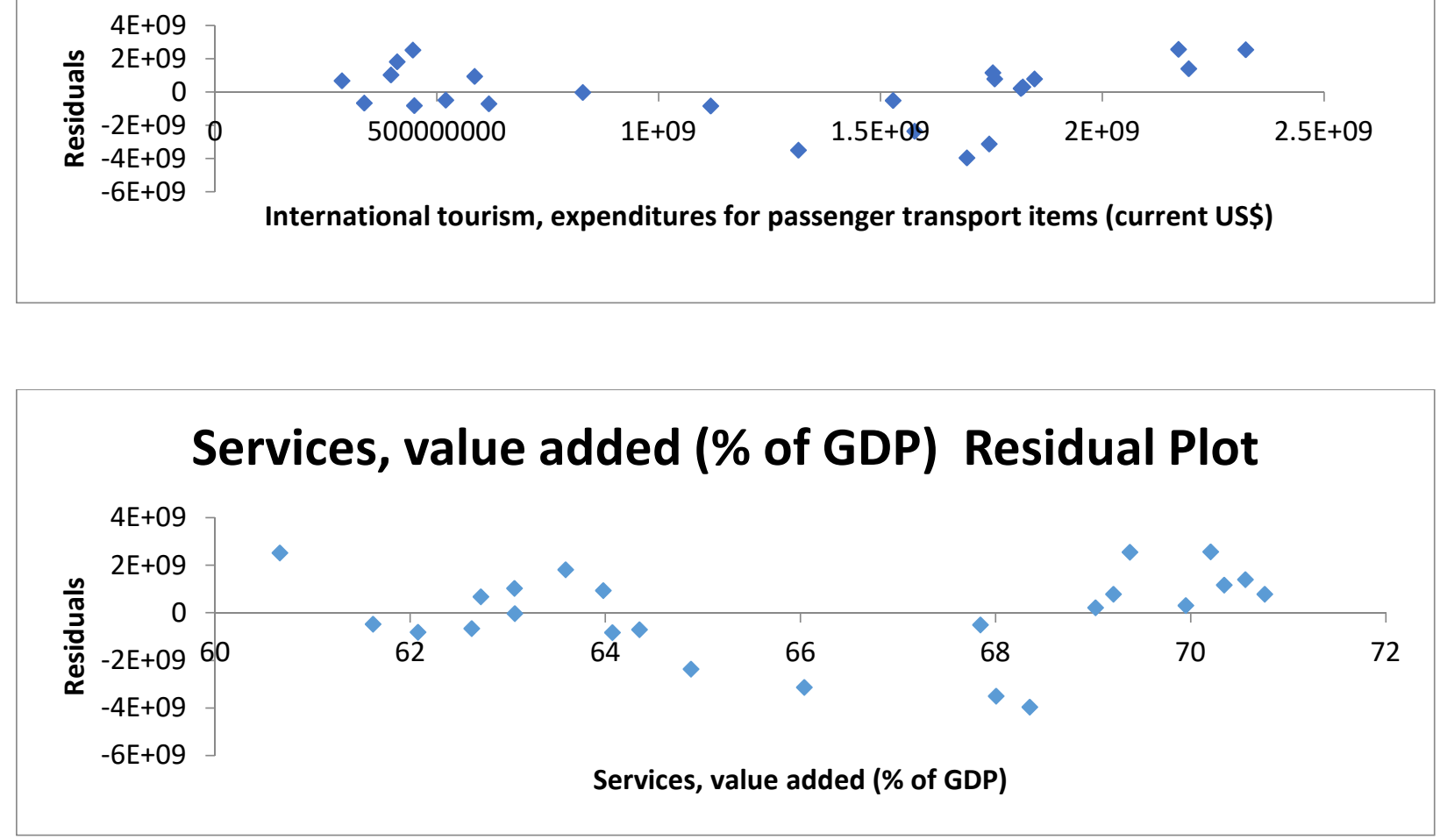

Table 5: Exchange Rate, Medical Tourism\& Service Sector with International Tourism Receipts Line Fit Plot for Singapore

From the Loess curve, it appears that the relationship of standardized predicted to residuals is roughly linear around zero. The results conclude that the relationship between the response variable and predictors is zero since the residuals seem to be randomly scattered around zero.

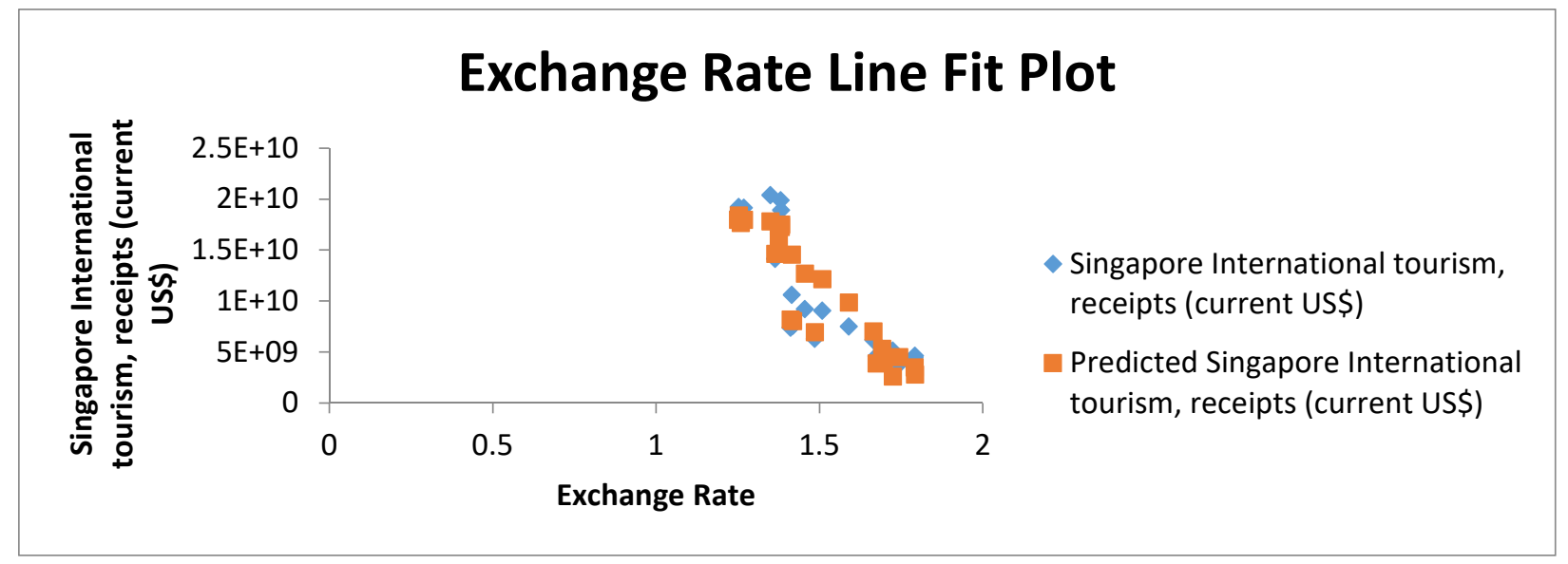



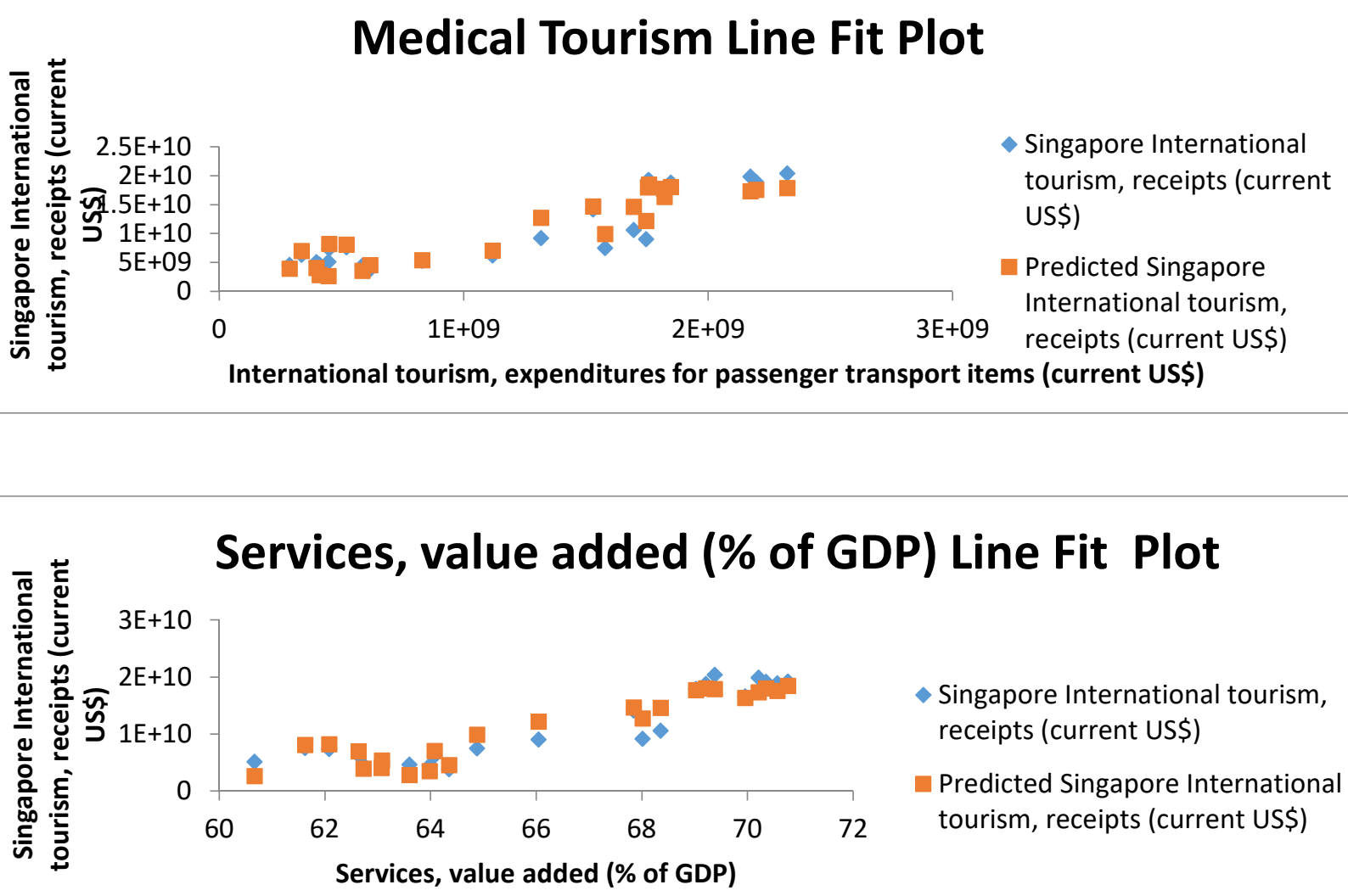

Table 6 : Normal Probability Plot for Singapore

The normal distribution appears to be a good model for these data.

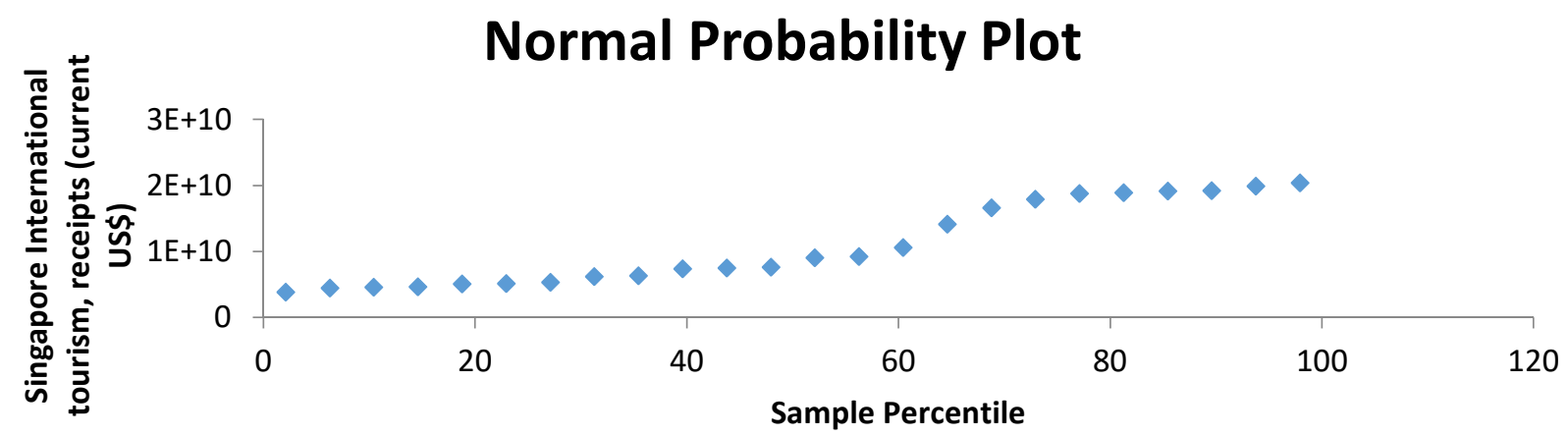

Visually, the probability plot shows a strongly linear pattern. This is verified by the correlation coefficient of medical tourism, exchange rate and service sector of the line fit to the probability plot. The fact that the points in the lower and upper extremes of the plot do not deviate significantly from the straight-line pattern indicates that there are not any significant outliers (relative to a normal distribution). In this case, the results can quite reasonably 
conclude that the normal distribution provides an excellent model for the data. The intercept and slope of the fitted line give estimates of all variables fitted normal distribution.

\section{REGRESSION ANALYSIS}

Table 7 : Summary Output Model Singapore

\begin{tabular}{lr}
\hline \multicolumn{2}{c}{ Regression Statistics } \\
\hline Multiple R & 0.989814633 \\
R Square & 0.979733008 \\
Adjusted R Square & 0.930183771 \\
Standard Error & 1901451523 \\
Observations & 24 \\
\hline
\end{tabular}

\begin{tabular}{|c|c|c|c|c|c|}
\hline & $d f$ & $S S$ & $M S$ & $F$ & $\begin{array}{c}\text { Significance } \\
F\end{array}$ \\
\hline Regression & 3 & 3.67036 & 1.22345 & 23.884 & .000 \\
\hline Residual & 21 & 7.59259 & 3.61552 & & \\
\hline Total & 24 & 3.74628 & & & \\
\hline
\end{tabular}

\begin{tabular}{lrrrr}
\hline & Coefficients & Standard Error & t Stat & value \\
\hline & - & & & \\
Exchange Rate & 15687988282.33 & 2750671769.26 & -5.70 & 0.00 \\
Medical Tourism & 2.81 & 1.05 & 2.67 & 0.01 \\
$\begin{array}{l}\text { Services, value added (\% of } \\
\text { GDP) }\end{array}$ & 468301312.50 & 79182283.84 & 5.91 & 0.00 \\
\hline
\end{tabular}

The regression analysis is the method that the variation across entities is assumed to be correlated and uncorrelated with the predictor or independent variables included in the model. The regression analysis is to explore the relationship between predictor and outcome variables. Each entity has its own individual characteristic that may or may not influence the opinion. Based on the Table 10, the model result of $\mathrm{R}$ square value is 0.98 which indicates that $98 \%$ of the dependent variable of tourism performance can be predicted by independent variables. The adjusted $\mathrm{R}$ square is 0.93 which indicated that model is a fit model, as the value is more than 0.60 (Gujarati, 2004). The higher the data fits to the observations when there is a higher the value. Table 10 shows that the ANOVA was test to justify the value of significant of all the independent variable and dependent variable. As the value of the significant shows that 0.000 which indicated that the value is significant because the value is less than 0.05 . As a result, the ANOVA model also shows that the $F=23.884$ referred by the value of statistically significant. 


\section{Conclusion}

Medical tourism is a fast-growing industry as globalization has made it easy for patients to travel to another country for healthcare. Its spillover effects to other industries provide a good source of revenues to any economy. The table above has include the coefficient value, the tstatistic value and the $\mathrm{P}$ value to analyze whether which of this variable is being accepted by using the regression analysis. The t-statistic will be rejected if the value is more than 1.96 and accepted if the value is less than 1.96. The $\mathrm{P}$ value will be accepted if the value is more than 0.05 and rejected if it is less than 0.05 . Firstly, we start with the exchange rate. The t-statistic and $\mathrm{P}$ value for the exchange rate is -5.7 and 0.00 respectively. This shows exchange rate is being accepted significant relationship with tourism performance at the. Next variable is medical tourism at this regression method the t-statistic value and $\mathrm{P}$ value is 2.67 and 0.01 respectively shows that medical tourism is accepted in this regression and have positive significant relationship with tourism performance. Lastly, service sector at regression method the t-statistic value and $\mathrm{P}$ value is 5.91 and 0.00 respectively shows that service sector is accepted by the regression method. It is now lagging behind Thailand and Malaysia for medical patients from Indonesia and the Middle East. The changing landscape of medical travel over the years has posed tremendous challenges to Singapore's economy.

\section{References}

[1] Adam P. Balcerzak, M. Ż. (2011). Foreign Direct Investment and Unemployment: VAR Analysis for Poland in the Years 1995-2009. Foreign Direct Investment and Unemployment: VAR Analysis for Poland in the Years 1995-2009.

[2] Aigner, D. J. (1984).Latent variable models in econometrics.Latent variable models in econometrics.

[3] Aizenman, J. (2005). FDI and Trade - Two Way Linkages?FDI and Trade - Two Way Linkages?

[4] Alfaro, L. (2003). Foreign Direct Investment and Growth: Does the Sector Matter? . Foreign Direct Investment and Growth: Does the Sector Matter? .

[5] Biørn, E. (1992). Econometrics of panel data with measurement errors.Econometrics of panel data with measurement errors.

[6] Buckley, P. J. (2007). The Determinants of Chinese Outward Foreign Direct Investment.The Determinants of Chinese Outward Foreign Direct Investment.

[7] Li, M. (2006).Inflation and Economic Growth: Threshold Effects and Transmission Mechanisms.Inflation and Economic Growth: Threshold Effects and Transmission Mechanisms.

[8] licaiLv, S. W. (2010). Determinants and performance index of foreign direct investment in China's agriculture. Determinants and performance index of foreign direct investment in China's agriculture.

[9] Rashid, I. M. A., \&Razak, N. A. A. (2016).Determinants of Foreign Direct Investment (FDI) in Agriculture Sector Based on Selected High-income Developing Economies in OIC Countries: An Empirical Study on the Provincial Panel Data by Using Stata, 20032012.Procedia Economics and Finance, 39, 328-334.

[10] Rashid, I. M. A., \&Razak, N. A. A. (2017). Economic Determinants of Foreign Direct Investment (Fdi) in Agriculture Sector Based on Selected Developing OIC Countries: An Empirical Study on the Provincial Panel Data by Using Stata, 2003-2012. JurnalIntelek, 12(1). 
[11] Somasekar, J. \& Sharma, A. \& Reddy, N. \& Reddy, Y..(2020). IMAGE ANALYSIS FOR AUTOMATIC ENUMERATION OF RBC INFECTED WITH PLASMODIUM PARASITES-IMPLICATIONS FOR MALARIA DIAGNOSIS.Advances in Mathematics: Scientific Journal. 9. 1221-1230. 10.37418/amsj.9.3.48.

[12] A. SHARMA1 AND J. SOMASEKAR"Contrast Image Construction Technique for Medical Imaging" published in Advances in Mathematics: Scientific Journal (Adv. Math., Sci. J.) vol-9-no-6-2020 (pp 3325-3329)

[13] RohiniGoel, Avinash Sharma, and Rajiv Kapoor, "Object Recognition Using Deep Learning" published in Journal of Computational and Theoretical NanoscienceVol. 16, 4044-4052, 2019

[14] Santosh, Mamta\& Sharma, Avinash.(2019). A Proposed Framework for Emotion Recognition Using Canberra Distance Classifier.Journal of Computational and Theoretical Nanoscience.16. 3778-3782. 10.1166/jctn.2019.8250.

[15] MamtaSantosh, Avinash Sharma, "Facial Expression Recognition using Fusion of LBP and HoG Features" published in International Journal of Innovative Technology and Exploring Engineering (IJTTEE) ISSN: 2278-3075, Volume-8 Issue-8 June, 2019

[16] Varsha, N. Kumar, Energy Efficient TABU Optimization Routing Protocol for WSN,IngenieríaSolidaria, Universidad Cooperativa de Colombia, Issue- 33, July 2020.

[17] Muskan Jindal; EshanBajal; AlakanandaChakraborty; Prabhishek Singh, Ph.D; ManojDiwakar; Neeraj Kumar, “A Novel Multi-Focus Image Fusion Paradigm: A Hybrid Approach", Materials Today: Proceedings,Elsevier, 2020.

[18] ManojDiwakar, AmrendraTripathi, Kapil Joshi, MinakshiMemoria , Prabhishek Singh, Neerajkumar, "Latest Trends on Heart Disease Prediction using Machine Learning and Image Fusion", Materials Today: Proceedings,Elsevier, 2020.

[19] ManojDiwakar; AmrendraTripathi; Kapil Joshi; Ayush Sharma; Prabhishek Singh; MinakshiMemoria; Neeraj Kumar, "A Comparative Review: Medical Image Fusion using SWT and DWT", Materials Today: Proceedings,Elsevier, 2020.

[20] ParthWadhwa; Aishwarya; AmrendraTripathi; Prabhishek Singh; ManojDiwakar; Neeraj Kumar, "Predicting the Time Period of Extension of Lockdown due to Increase in Rate of COVID-19 Cases in India using Machine Learning", Materials Today: Proceedings Elsevier, 2020.

[21] Awadhesh Kumar Maurya,Varsha, Neeraj, Ajay Kumar, Neeraj Kumar, "Improved chain based cooperative routing protocol in wsn", FEST, Journal of Physics: Conference series, IOP Publishing, 1478,1-8, 13/05/2020.

[22] V. Velvizhi; Satish R Billewar; GauravLondhe; PravinKshirsagar; Neeraj Kumar, "Big Data for Time Series and Trend Analysis of Poly Waste Management in India", Materials Today: Proceedings, Elsevier, 2020.

[23] N. Kumar, A. Agrawal,R. A. Khan, "METHWORK: An Approach for Ranking in Research Trends with a Case Study for IoET, Recent advances in Computer Science and Communication (formerly Recent Patents on Computer Science), 2019.

[24] Kumar, Neeraj, AlkaAgrawal, and R. A. Khan. "Cost estimation of cellularly deployed IoT-enabled network for flood detection." Iran Journal of Computer Science, issue 2, no. 1 (2019), Springer Nature: 53-64.

[25] A. Kumar Maurya, G. Arora, A. Arora and N. Kumar, "Security Issues in Cloud based Infrastructure: A Review", Journal of advanced research in dynamic control systems, Vol. 10, 14 Special Issue, 2018. 